\title{
The use of a new miniature cryoprobe for ablation of bone tissue: In vivo assessment of the probe and application of the method to bone in a sheep model
}

\author{
Frank Popken*1, Marc Land1, Heike Erberich³ ${ }^{3}$ Marfalda Bosse ${ }^{2}$, Dietmar- \\ Pierree König ${ }^{1}$ and Peer Eyse ${ }^{1}$
}

\author{
Address: ${ }^{1}$ Department of Orthopedic Surgery, University of Cologne, Josef-Stelzmann-Str. 9, 50931 Cologne, Germany, ${ }^{2}$ Institute of Experimental \\ Medicine, University of Cologne, Robert-Koch-Str. 10, 50931 Cologne, Germany and 3 Institute of Pathology, University of Cologne, Josef- \\ Stelzmann-Str. 9, 50931 Cologne, Germany \\ Email: Frank Popken* - fpopkenm@aol.com; Marc Land - Land167@aol.com; Heike Erberich - ha.erberich@uni-koeln.de; \\ Marfalda Bosse-m.bosse@uni-koeln.de; Dietmar-Pierree König - Dietmar-Pierre.Koenig@medizin.uni-koeln.de; Peer Eysel - peer.eysel@uni- \\ koeln.de \\ * Corresponding author
}

This article is available from: http://www.biomedcentral.com/I47/-2482/3/3

(C) 2003 Popken et al; licensee BioMed Central Ltd. This is an Open Access article: verbatim copying and redistribution of this article are permitted in all media for any purpose, provided this notice is preserved along with the article's original URL.

\begin{abstract}
Background: So far, modern miniature cryoprobes were used for local destruction of soft tissue tumours without damaging the adjacent healthy tissue. In this study, cryoablation methodology was applied to bone and the cooling capacity of the probe was examined in vitro and in vivo.

Method: Freezing was performed by cooling one or two probes (diameter $3.2 \mathrm{~mm}$ ) to $-180^{\circ} \mathrm{C}$ with liquid nitrogen. The cooling capacity of the probes was determined optically and thermally against a homogeneous reference gel, followed by in vivo measurements on femoral and tibial sheep bone followed by histological examination.

Results: Thanks to the synergistic effect, the simultaneous use of 2 probes produced an almost spherical expansion of cold in the homogenous gelatin. During the in vivo freezes, the temperature curves showed a more moderate trend. Nevertheless, due to the synergistic effect, temperatures below $-50^{\circ} \mathrm{C}$ could be reached at a distance of $\mathrm{I} \mathrm{cm}$ from the probe. No local or systemic intraoperative complications were observed. Histological examination revealed cell necrosis up into the $-10^{\circ} \mathrm{C}$ isotherm.

Conclusions: Adequate tissue cooling of the bone matrix can be achieved with in vivo freezes by means of one or more miniature cryoprobes. Therefore, this probe could provide an alternative to or supplement surgical resection of pathological bone processes.
\end{abstract}

\section{Background}

Surgical treatment of bone tumours often requires a generous resection of bone, leaving defects which are difficult to span. The method of freezing tumours with liquid nitrogen was introduced as an adjunct treatment to intralesional resection, or curettage for extension of the surgical 

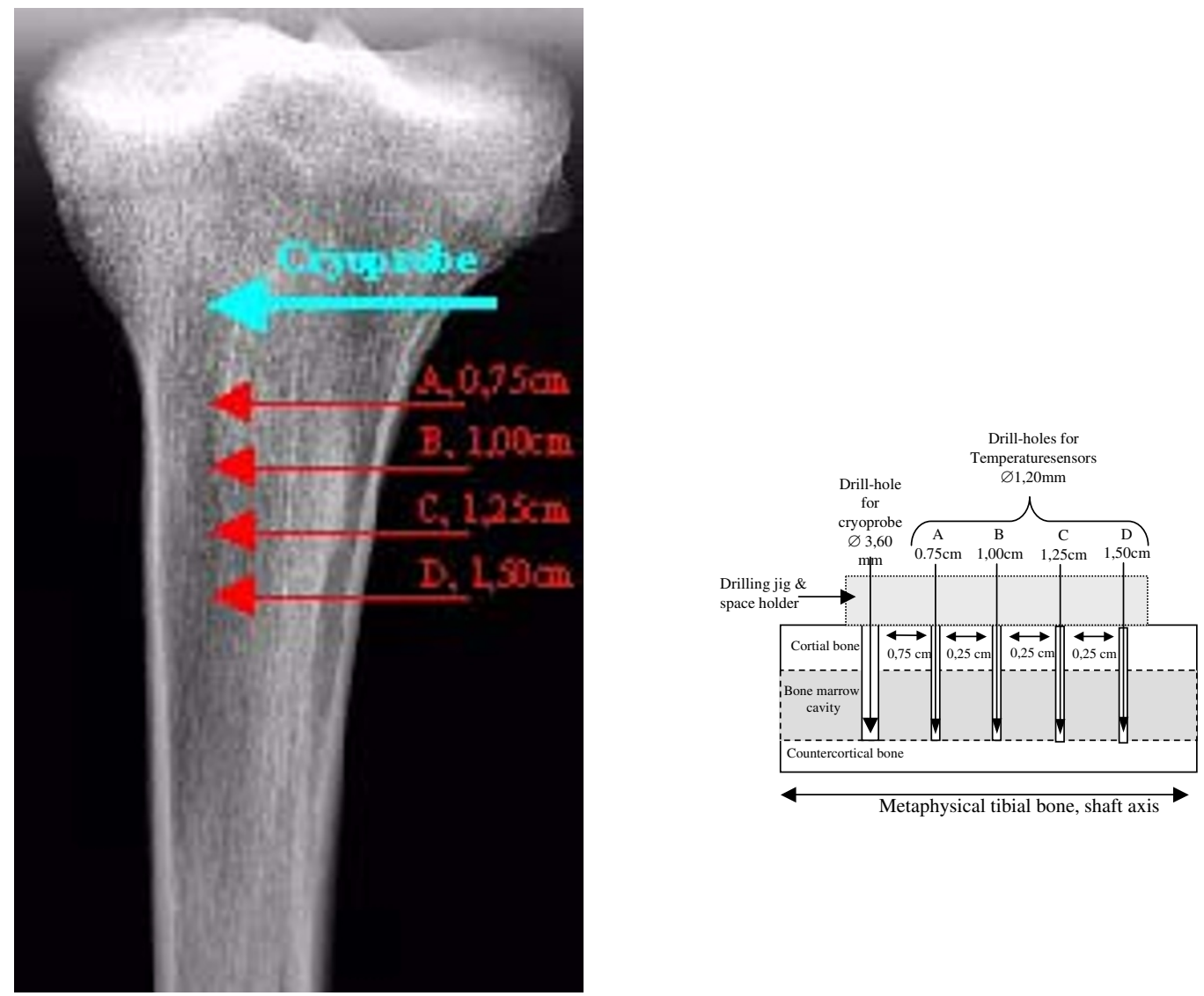

\section{Figure I}

One active cryoprobe in vital metaphysial bone (proximal tibia) Fig. Ia: Experimental set up using one cryoprobe on the tibial metaphysis Two active cryoprobes in vital diaphysial bone (femoral diaphysis) Fig. Ib: Experimental set up simultaneously using two cryoprobes

margin of excision. The nitrogen was poured or sprayed directly into the bone cavity $[11,13,14,16,24-27]$. Due to minimal control of the freezing procedure $[12,15]$ and the risk of vaporization causing gas emboli [23], the widespread use of direct application of nitrogen was limited.

In addition to open application, a closed system has also been described $[5,6,9]$. For the first time in 1984, Russe and Kerschbaumer used cryoprobes for ablation of bone tumours in humans [21]. The probes were bent, trocarlike, hemispherical or spherical [10], but their cooling ability was poor in relation to the probe's diameter $[4,8]$. This was mainly due to evaporation of the nitrogen inside the system before it actually reached the freezing zone. Therefore, less nitrogen was available at the tip of the probe, which in turn limited the speed of freezing and the minimum temperature attainable, as well cell destruction [7].

As described by Baust et al. in 1997, the boiling point is lowered by increasing the pressure within the device, thereby preventing premature evaporation [2]. In the Erbokryo CS- 6 cryoprobe used here, evaporation is prevented almost completely by an operating pressure of $15 \mathrm{bar}$ at the beginning of the freezing process and by an optimum flow of nitrogen. This ensures quick exposure of the surrounding tissue to the low temperature. Pressure is lowered during freezing, which raises the boiling point of the nitrogen to ensure evaporation of the nitrogen at the tip of the probe, and hence a further drop in temperature in the surrounding tissue. Furthermore, unnecessary tissue injury caused by insertion of the probe was avoided by 

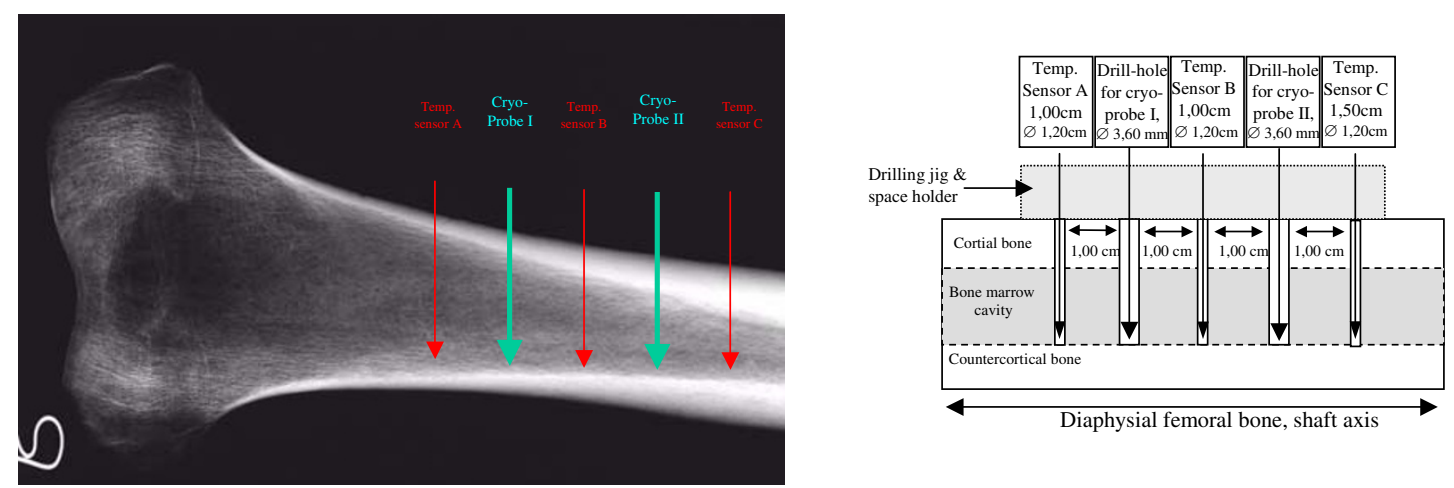

Figure 2

Gelatin - I cryoprobe vertical measurement

reducing the probe's diameter to $3.2 \mathrm{~mm}$. While the basic suitability of freezing for the destruction of bone tumours - also when using cryoprobes - has already been documented [21], the use of this high-capacity, fine-calibre miniature cryoprobe for freezing bone tissue has not yet been described. The goal of this in vitro and in vivo experiment was to establish the possible field of therapy for such a miniature cryoprobe in a reference medium and to study whether this miniature cryoprobe is suitable for appropriate tissue cooling in long bones.

\section{Methods}

The Erbokryo CS- 6 System is a commercially available cryotherapy device which consists of a device with a control unit and vacuum-isolated flexible tubes leading to the cryoprobes. The case also contains a 47 liter capacity vacuum-isolated tank (supply Dewar) with liquid nitrogen which is heated electrically. The probes are started by the resulting vapor pressure of up to 15 bar. The liquid nitrogen $\left(-196^{\circ} \mathrm{C}\right)$ reaches the $3 \mathrm{~cm}$ long freezing zone at the tip of the probe through a central delivery tube and then vaporizes through heat absorption. The flow of nitrogen can be chosen for each probe at four levels, from 25$100 \%$ up to a maximum flow rate of $1.5 \mathrm{l} / \mathrm{min}$. The nitrogen gas then flows through a coaxial external pipe back into the tank. A total of 6 cryoprobes can be used simultaneously.

In the first part of the experiment, a transparent gelatin was used at room temperature and the formation of ice crystals around a single probe as well as two coupled probes photographed every two minutes. At the same time, the temperature gradients were determined horizontally and vertically within the cold zone every minute using the computer-guided Erbekryo CS-6 temperature couples (Thermoelement Typ K, galvanically separated 


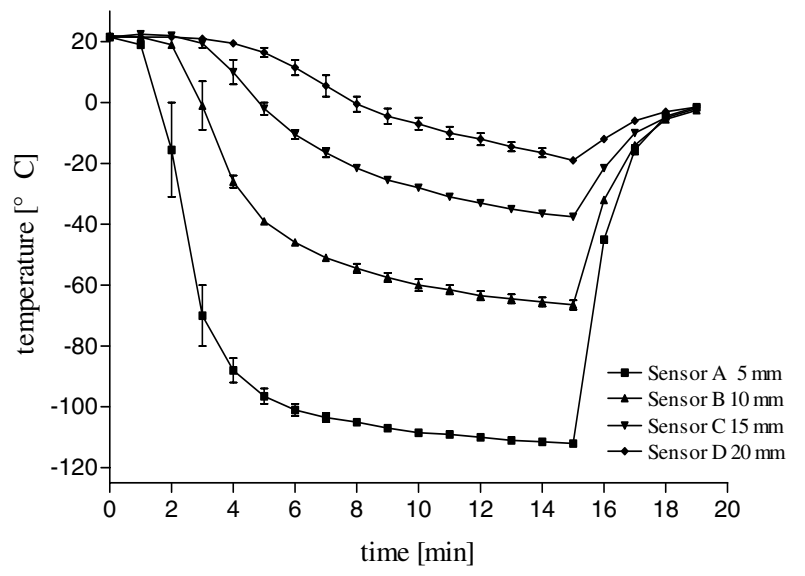

Figure 3

Gelatin - I cryoprobe horizontal measurement

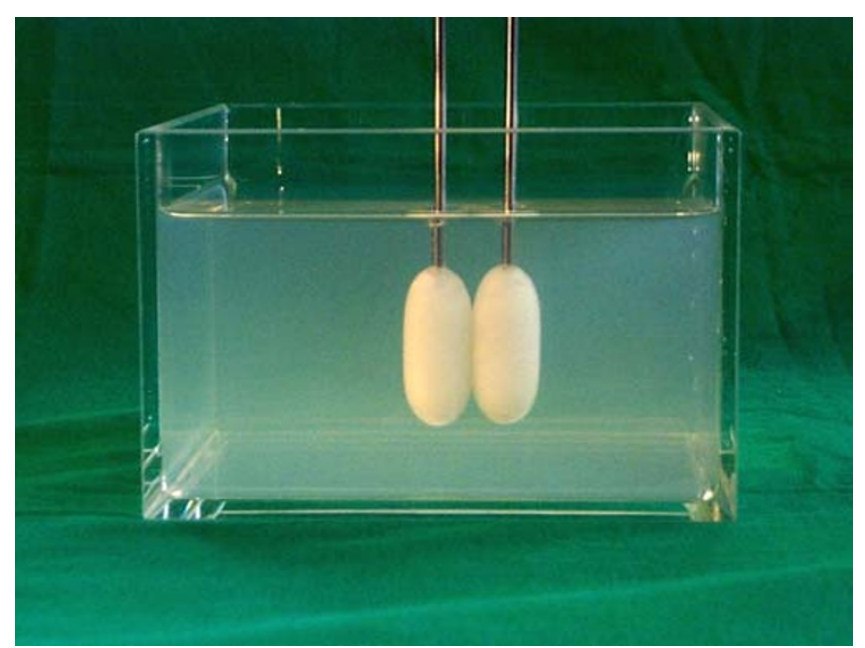

Figure 4

Initial melting of the ice crystals at the equator of both edges

channels, 6 separate BF type channels for external temperature measurement) which allow up to 6 temperature measurements simultaneously. These sensors, which have a diameter of $1.1 \mathrm{~mm}$, were placed by eye every $0.5 \mathrm{~cm}$ at a distance of $2 \mathrm{~cm}$ from the centre of the probe using a special plexiglass holder. The vertical measurement was carried out in $1 \mathrm{~cm}$ intervals from the probe over the entire freeze zone. For the simultaneous use of two probes $2 \mathrm{~cm}$ apart, temperature distributions were determined halfway between the two probes and diametrically at $1 \mathrm{~cm}$ intervals around each probe. Four different measurements were carried out for each trial, each in gelatin with different probes (all by the same manufacturer).

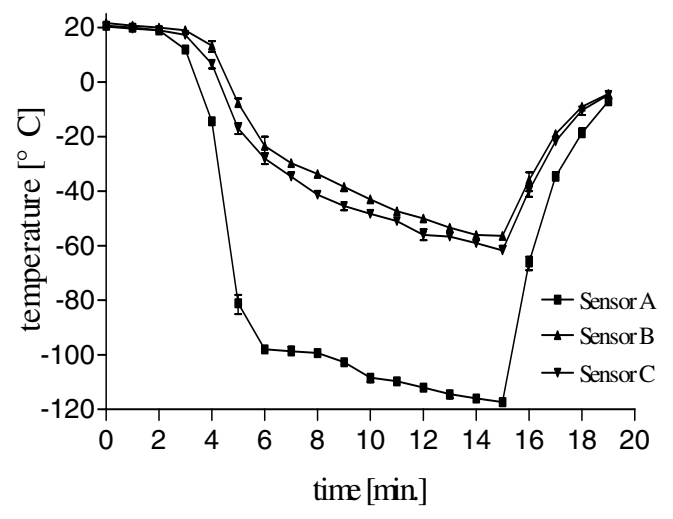

Figure 5

Gelatin - 2 cryoprobes horizontal measurement

In the second part of the experiment, a total of 4 freezes were carried out on both hind legs of a sheep under general anaesthesia. Holes $3.6 \mathrm{~mm}$ in diameter were drilled perpendicular to the shaft axis (Fig. 1a/1b). The cryoprobes were introduced and the remaining space filled with $10 \% \mathrm{NaCl}$ solution as a coupling medium. The proximal tibial metaphysis was frozen using one cryoprobe (Fig. 1a) and then the distal diaphysis-metaphysis transition area of the femur was frozen using two probes as described for the in vitro freezings (1b). The thermocouples were introduced into the drilling holes (diameter 1.2 $\mathrm{mm}$ ) at distances of $7.5 \mathrm{~mm}, 10 \mathrm{~mm}, 12.5 \mathrm{~mm}$ and 15 $\mathrm{mm}$ from the center of the cold area using one cryoprobe (Fig. 1a) and, using two probes simultaneously, at a distance of $10 \mathrm{~mm}$ (Fig. 1b). The exact position of the cryoprobes and the thermocouples was checked radiologically. Measurements were taken at one-minute intervals using a computer. Thermal influence of the measurement on the opposite side was avoided by alternating the freezings. Intraoperative control of blood pressure, heart rate, body temperature and acid-base balance (periodic blood gas analysis) were checked to detect potential complications.

One week postop the animal were sacrificed and the extent of necrosis determined histologically. The bone segments were decalcified (ethylene diamine tetraacetic acid), embedded in Technovit 7100 and sectioned for hematoxylin-and-eosin staining. The results of the trials and statistical evaluation were done in SPSS for Windows, Version 9.0. 


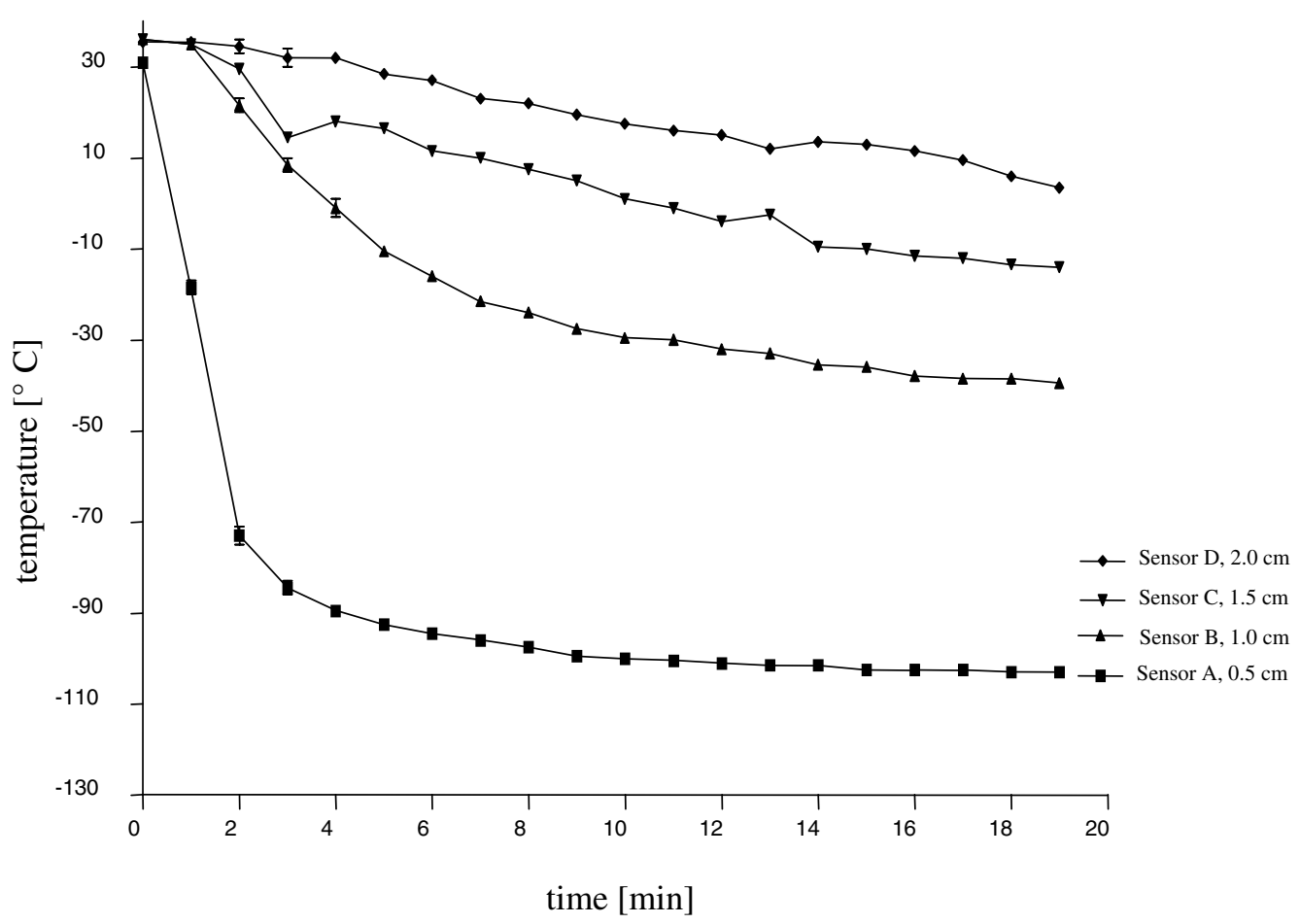

Figure 6

In-vivo metaphyseal bone - I cryoprobe

\section{Results}

\section{Cryoprobe in gelatin}

After freezing was initiated with the maximum nitrogen flow rate, a spindle-shaped ice formation began to form, radiating outwards from the freezing zone, progressively becoming more spherical. Analogous to these observations, it was shown that the vertical freezing capacity of the probe was greatest in the middle part of the cold zone (Fig. 2). Even after 8 minutes, a temperature of $-51 \pm$ $2.9^{\circ} \mathrm{C}$ was measured on sensor $\mathrm{C}$ (Fig. 2) while an average temperature of $-22.5 \pm 4.1^{\circ} \mathrm{C}$ was read at the distal and the proximal ends of the cold zone (sensors A and D, Fig. 2). Even after 15 minutes, at the end of the freeze, the temperature in the centre of the cold zone was lower with -48.6 $\pm 4.6^{\circ} \mathrm{C}$ (sensor B, Fig. 2) and $-61.5 \pm 1.5^{\circ} \mathrm{C}$ (sensor C, Fig. 2 ). On the other hand, temperatures at the end of the cold zone were measured at $-34 \pm 3.7^{\circ} \mathrm{C}$ (sensor B, Fig. 2) and $-36 \pm 4.5^{\circ} \mathrm{C}$ (sensor A, Fig. 2).
The time- and place-dependent decrease in temperature in the horizontal direction is shown as a system of curves, with the distance of the sensors from the tip of the probe as the variable (Fig. 3). The temperature drop at the beginning of freezing near the probe ( $5 \mathrm{~mm}$, sensor A, Fig. 3) was very steep, with a maximum of $49 \pm 18.0^{\circ} \mathrm{C}$ per minute between the first and the second, as well as the second and the third minute after beginning of freezing. More than $90 \%\left(-106^{\circ} \mathrm{C}\right)$ of maximum cooling $\left(-113^{\circ} \mathrm{C}\right)$ was achieved after only 7 minutes. With increasing distance from the probe and duration of freezing, the cooling rate decreased markedly (temperature decrease per minute); e.g., a distance of $10 \mathrm{~mm}$ from the probe required 8 minutes after beginning of freezing to reach a temperature of $-50^{\circ} \mathrm{C}$. A maximum cooling rate of $27^{\circ} \mathrm{C} /$ minute was reached between the second and the third minute after beginning of freezing. The temperature drop at a distance of $20 \mathrm{~mm}$ from the probe (sensor D, Fig. 3) 


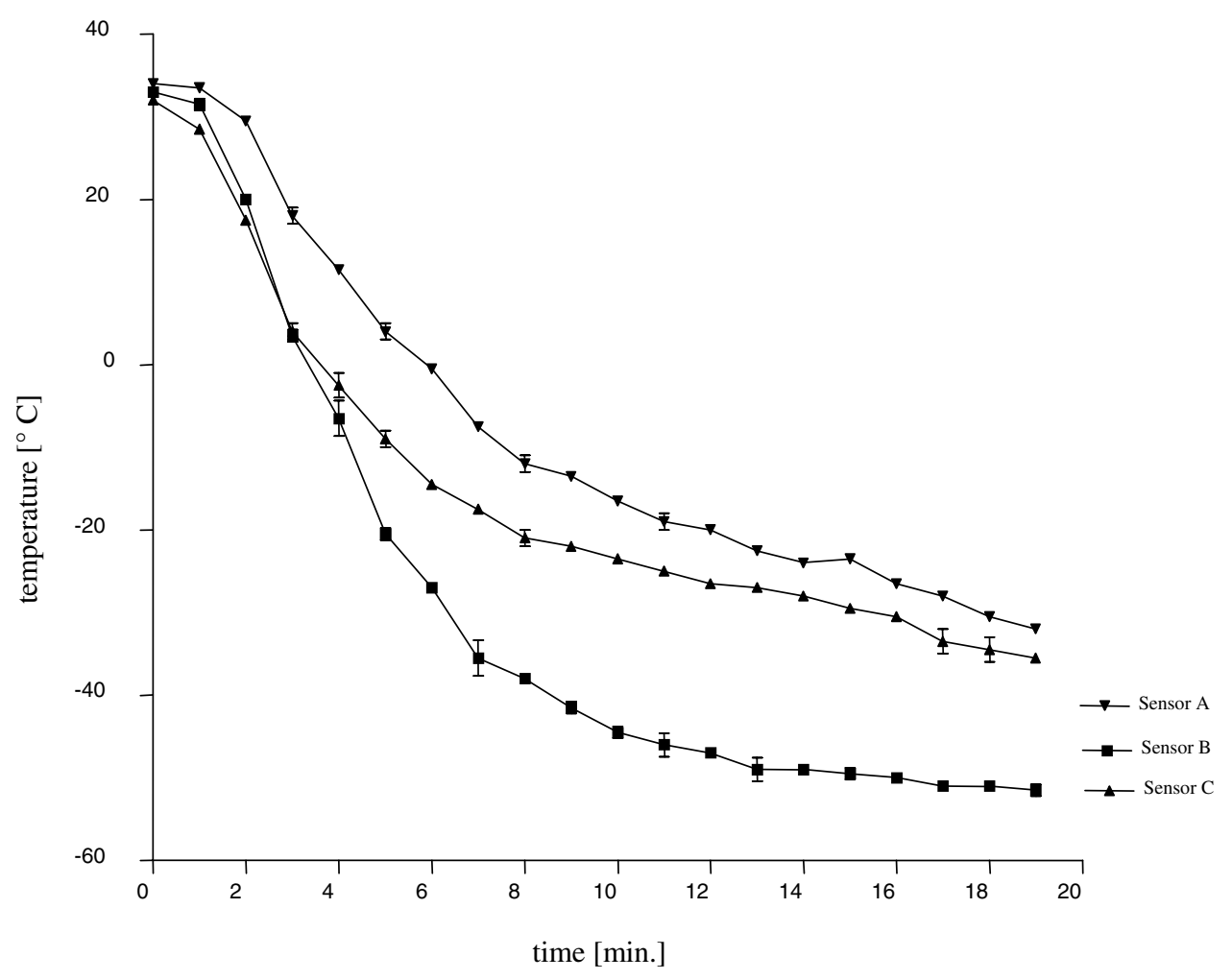

Figure 7

In-vivo metadiaphyseal bone -2 cryoprobes

is nearly linear, with a maximum value of $7 \pm 1.77^{\circ} \mathrm{C} /$ minute.

\section{Two cryoprobes in gelatin}

To the eye, there was no difference in freezing when a single probe was employed compared to when two cryoprobes were used simultaneously. As the edge of the cold zone advanced, there was an initial melting of the ice crystals at the equator of both edges (Fig. 4). Later on, the crystals merged into a confluent sphere. After 15 minutes, at the end of freezing, the ice sphere was $7 \pm 0.9 \mathrm{~cm}$ wide and $6.4 \pm 0.7 \mathrm{~cm}$ high. Fig. 5 shows the change in temperature as a function of the freezing time between two active cryoprobes (sensor A, Fig. 5), as well as the synchronous temperature measurements next to both probes (sensors B and C, Fig. 5). A synergistic freezing effect was seen between the probes, with a higher cooling rate of up to $66^{\circ} \mathrm{C}$ between the fourth and the fifth minute of freezing, as well as a much lower minimum temperature of $-117^{\circ} \mathrm{C}$, compared to the measurements in the same intervals when using only one probe $\left(\leq-60^{\circ} \mathrm{C}\right)$.

\section{In vivo freezing}

The decrease in temperature was less pronounced when freezing living bone with one cryoprobe than for the in vitro measurements (Fig. 6). The ice front also did not spread as far. Analogous to the in vitro trials, the highest rate of cooling was measured near the probe $(5 \mathrm{~mm}$, sensor A, Fig. 6), where the temperature sank to $-77 \pm 3{ }^{\circ} \mathrm{C}$. Even at a distance of $10 \mathrm{~mm}$ from the probe, a temperature of $-41 \pm 2^{\circ} \mathrm{C}$ could be reached. Accordingly, as the distance from the probe increased, the temperature drop also was decreased.

The measurements with two cryoprobes show the synergistic freezing effects through the confluence of two freez- 


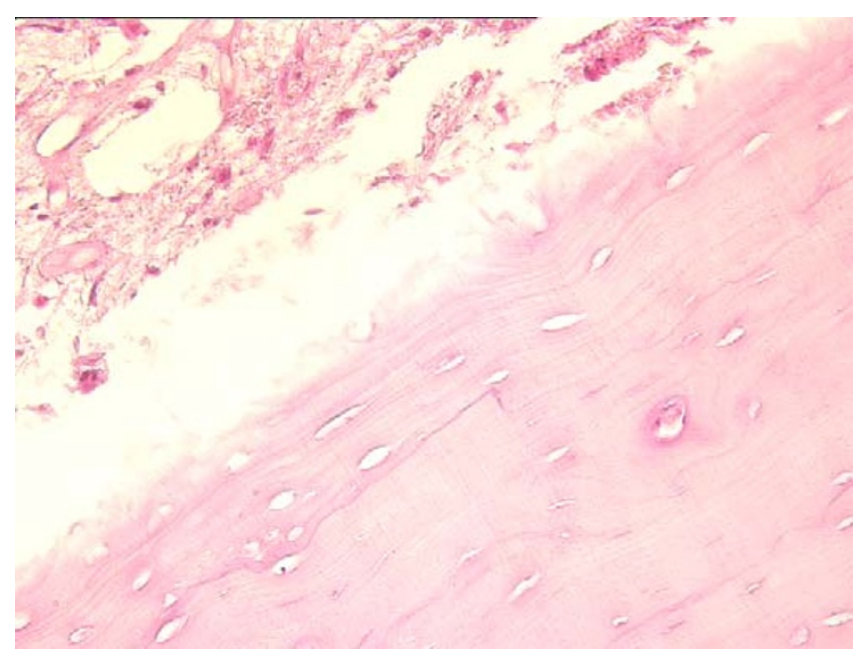

Figure 8

Total cortical necrosis with empty osteocyt lacuna and without detectable nucleous staining of the tibia

ing zones, which already was observed in the in vitro trials. The minimum temperatures reached between the probes, on the other hand, were higher than in vitro because of the body heat of the animals. Nevertheless, with a temperature of $-65^{\circ} \pm 3^{\circ} \mathrm{C}$ (sensor A, Fig. 7), this was lower than the corresponding measurement points $\mathrm{B}$ and $\mathrm{C}$ (Fig. 7), which were $1 \mathrm{~cm}$ away from only one probe. The temperatures reached here $\left(-39 \pm 4^{\circ} \mathrm{C}\right)$ corresponded approximately to the temperatures measured for one probe at the same intervals. No systemic or local intraoperative complications were observed.

Macroscopically, the cryosurgical-treated bone section showed a circular necrosis which was sharply bounded and distinct from neighbouring bone and marrow tissue. Histological examination showed an extension of the bone necrosis corresponding to the $-10^{\circ} \mathrm{C}$ isotherm (Fig. 8 ), with a continuous transition from full necrosis to vital bone (Fig. 9). The marrow necrosis is more homogeneous, extends much farther and passes the region of compact bone necrosis by about $2 \mathrm{~cm}$.

\section{Discussion}

The open use of nitrogen requires exposition and generous fenestration of bone with a limited penetration of freezing [26]. Ideally, liqiud nitrogen should be applied while avoiding trauma to the surrounding healthy soft tissue to ensure the least additional destabilization of the bone when accessing the tumour. In contrast, earlier cryoprobes were less suitable for this purpose due to poor design and performance [4,8]. Modern miniature cryoprobes, such as those used in this study, seem to be more suitable. Precise knowledge of the thermal properties of the probe is an absolute prerequisite, as is familiarity with the expansion of the cold zone over time because both the tumour and the tumour-infiltrated bone tissue bordering the tumour are left in place.

In order to determine the cooling performance of the cryoprobe, and in order to be able to follow the freezing process visually, freezing was first done as described by Saliken et al. (see below) and Rewcastle et al. $[19,20]$ in a homogeneous, transparent reference medium (gelatin). The cold zone expanded in a circle around the cryoprobe and cooled the gelatin to less than $-60^{\circ} \mathrm{C}$ at a distance of $1 \mathrm{~cm}$ from the centre of the probe. This freezing differs from those described by Saliken et al. [22] and Rewcastle et al. [19], where different cryoprobes with a comparable cooling capacity and calibre were tested under nearly identical conditions. While the cooling performance of the cryoprobe used by Rewcastle et al. is lower, the edge of the cold zone Saliken observed showed not only somewhat lesser cooling at the corresponding sensors, but also a pear-shaped growth pattern. The use of this probe in the treatment of prostate carcinomas [1] is anatomically advantageous. The prolate field of therapy of the miniature cryoprobe (maximum expansion at the centre of the freezing zone) tested here would be better suited to ablation of bone tumours because even expanded tumours can be treated this way, the probe being centrally inserted and gradually pulled back following one or more freeze-andthaw cycles [7]. The freezing trials with two probes showed that simultaneous use of more miniature probes creates a synergistic freezing effect as decribed by Saliken [22], Berger [2] and Rewcastle [20] with overlap of both therapy fields. There is a maximum effect after 15 minutes and at a distance of $2 \mathrm{~cm}$ between probes; e.g., the Erbokryo CS-6 allows simultaneous ablation with 6 probes to create a tubular field of therapy of at least $14 \mathrm{~cm}$ in length, thus allowing optimum treatment of diaphyseal tumours.

As expected, when employing this methodology to bone at body temperature and with circulating blood gave more moderate temperature curves during freezing, both when one or two probes.

The lowest tissue temperature, the prime factor in cell death, should be $-50{ }^{\circ} \mathrm{C}$ [7] or less [3] in neoplastic tissue. Hence, only lesions or tumour-infiltrated bone tissue of about $1.50-2.00 \mathrm{~cm}$ or less can be successfully treated with a single $3.2 \mathrm{~mm}$ miniature cryoprobe. When applying two adjacent cryoprobes simultaneously, our diaphyseal measurements showed a synergistic freezing effect resuting in $\mathrm{a}-50^{\circ} \mathrm{C}$ isotherm of up to $3.00-3.50 \mathrm{~cm}$ in diameter. Parting from the recommendations by Baust et al., that the cryosurgeon should aim for a temperature of - 


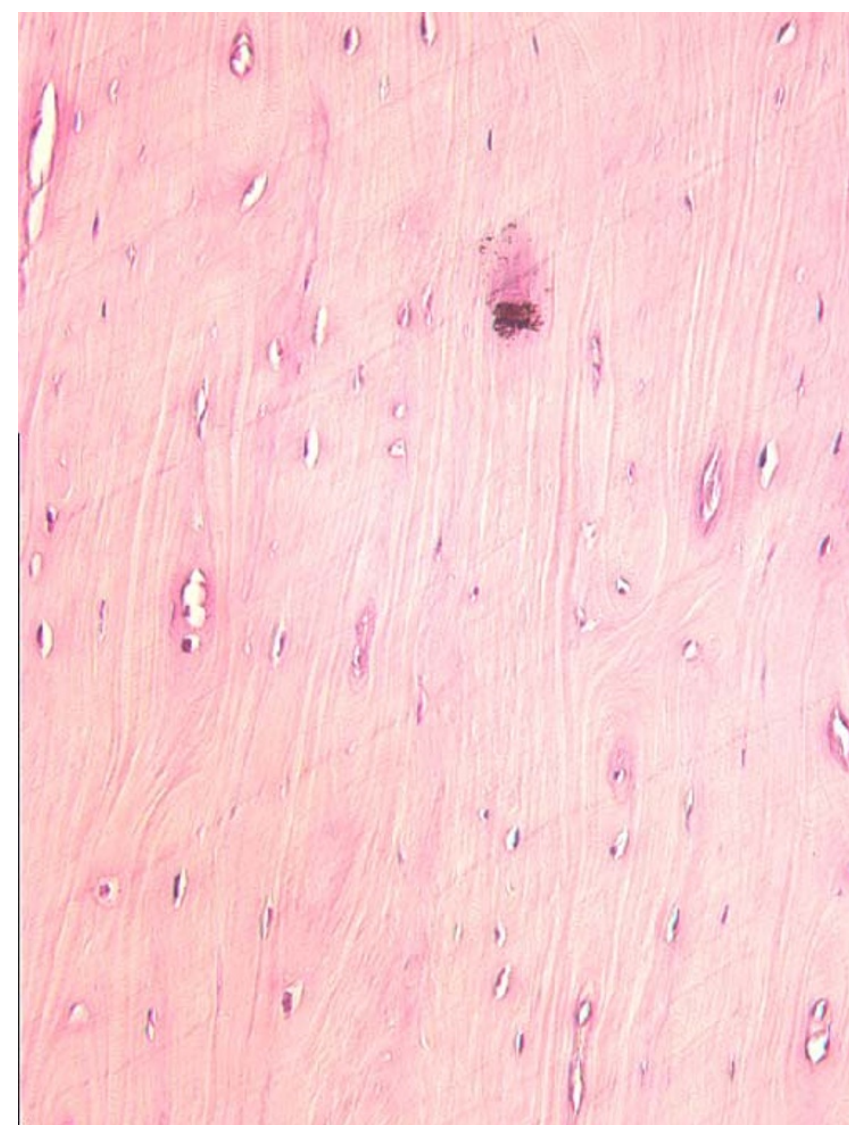

Figure 9

In contrast a healthy areal of the same sheep and the same tibia with stained nucleus of the osteocyts

$30^{\circ} \mathrm{C}$ in the periphery of the abnormal tissue [3], then the areas potentially treatable with one or two probes would have to be planned accordingly larger.

This study was done on non-malignant bone lesions and not on malignant bone tissue because our main goal was to test the fundamental applicability of this new probe under in vivo conditions in relatively human-like organisms. No tumour models have been bescribed in large animals. Nevertheless, our data can be applied to cryosurgery of malignant bone tissue because freezing at the edge of the dysplastic area, which consists mainly of non-dysplastic bone tissue, is very important in preventing local recurrences.

In principle, the thickness of the $1.1 \mathrm{~mm}$ thermal feelers goes with a certain imprecision in measuring the temperature [18], although we made the experience that even if the access hole was drilled precisely, thinner feelers bend very quickly and so cause a much greater measruement error. Moreover, with the thermal feelers used here, temperature is not measured across the entire diameter, but only at the tip of an area some $0.2 \mathrm{~mm}$ thick, thus reducing artefacts to an acceptable range.

Neither local nor systemic complications were observed in the animals, which is consistent with the minimally invasive nature of cryosurgery, as was seen when the method was applied to other organs $[17,28]$. Although the quantity of individual trials was too low for statistical analysis, it is still evident that adequately low temperatures can be reached in vivo using the miniature cryoprobes that were used here.

Further trials with a larger number of animals have already begun. They need to document the effect the expansion of the zone of necrosis has on bone at body temperature and with a circulating blood. In addition, it is necessary to know the middle- and long-term effects that are to be expected following cryosurgery of bone. In the case of favourable results, cryosurgery with modern miniature probes could be a valuable adjunct to the resection of bone or, in certain cases, provide a viable alternative.

\section{References}

I. Bahn D, Lee F, Solomon H, Gontina H, Klionsky E and Lee F Jr Prostate cancer: US guided percutaneous cryoablation Radiology 1995, 194:551-556

2. Baust J, Gage AA, Ma H and Zhang C-M Minimally invasive cryosurgery-technological advances Cryobiology 1997, 34:373-384

3. Baust $J$ and Maiwand MO Fundamental Aspects of Cryosurgery Cryosurgery 2002, 6:6-8

4. Berger WK, Schüder G and Feifel G Temperaturverteilungsmuster im Lebergewebe bei Einfriervorgängen mit neuen Kryosonden Chirurg 1996, 67:833-838

5. Cooper IS and Cryogenic Surgery A new method of destruction or exstirpation of benign or malignant tissues New England J Med 1963, 268:743-749

6. Gage AA, Greene GW, Neiders ME and Emmings FG Freezing bone without excision. An experimental study of bone-cell destruction and manner of regrowth in dogs JAMA 1966, 1 96:770-774

7. Gage AA and Baust J Mechanisms of tissue injury in cryosurgery cryobiology 1998, 37(3): I7|-186

8. Hewitt PM, Zhao J, Akhter J and Morris DL A Comparative Laboratory Study of Liquid Nitrogen and Argon Gas Cryosurgery Systems Cryobiology 1997, 35:303-308

9. Kerschbaumer F, Weiser G, Neuerer G, Russe W and Bauer R Cryolesions of Bone. An Experimental Study. Part I: Examinations in technique of controlled cryolesion in bone Arch Orthop Trauma Surg 1980, 96:5-9

10. Kerschbaumer F, Russe W and Bauer R Grundlagen der Kryochirurgie in der Orthopädie Orthopäde 1984, I3:|33-|4|

II. Malawer MM, Bickels J, Meller I, Buch RG, Henshaw RM and Kollender $\mathrm{Y}$ Cryosurgery in the treatment of giant cell tumor. $A$ long-term followup study Clin Orthop 1999, 359:176-188

12. Marcove RC, Miller TR and Cahan WC The treatment of primary and metastatic bone tumors by repetitive freezing Bull $N Y$ Acad Med 1968, 44(5):532-544

13. Marcove RC and Miller TR Treatment of primary and metastatic bone tumors by cryosurgery JAMA I969, 207(1 0): 1890-1894

14. Marcove RC, Weis LD, Vaghaiwalla MR and Pearson R Cryosurgery in the treatment of giant cell tumors of bone: a report of 52 consecutive cases Clin Orthop 1978, 134:275-289 
15. Marcove RC, Weis LD, Vaghaiwalla MRT, Person R and Huvos AG Cryosurgery in the Treatment of Giant Cell Tumors of the bone Cancer 1978, 41:957-969

16. Marcove RC, Sheth DS, Brien EW, Huvos AG and Healey JH Conservative surgery for giant cell tumors of the sacrum. The role of cryosurgery as a supplement to curettage and partial excision Cancer 1994, 74(4): I 253-60

17. Morris DL, Ross WB, lqbal J, McCall JL, King J and Clingan PR Cryoablation of hepatic malignancy: An evaluation of tumour marker data and survival in I I0 patients GI Cancer 1996, I:47251

18. Rabin Y, Colemann R, Mordohovich D, Ber R and Shitzer A A new cryosurgical device for controlled freezing Cryobiology 1996, 33(I):93-105

19. Rewcastle JC, Sandison GA, Hahn LJ, Saliken JC, McKinnon JG and Donnelly $B J$ A model for the time-dependent thermal distribution within an iceball surrounding a cryoprobe Phys Med Bio 1998, 43(I 2):3519-3534

20. Rewcastle JC, Sandison GA, Muldrew K, Saliken JC and Donnelly BJ A model for the time dependent three-dimensional thermal distribution within iceballs surrounding multiple cryoprobes Med Phys 200 I, 28(6): I I 25-37

21. Russe W, Kerschbaumer $F$ and Bauer R Kryochirurgie in der Orthopädie Orthopäde 1984, I3(2): 142-150

22. Saliken JC, Cohen J, Miller R and Rothert M Laboratory evaluation of ice formation around a 3-mm Accuprobe Cryobiology 1995, 32:285-295

23. Schreuder HW, van Beem HB and Veth RP Venous gas embolism during cryosurgery for bone tumors J Surg Oncol 1995, 60(3): $196-200$

24. Schreuder HW, Conrad EU 3rd, Bruckner JD, Howlett AT and Sorensen LS Treatment of simple bone cysts in children with curettage and cryosurgery J Pediatr Orthop 1997, I7(6):8|4-820

25. Schreuder HW, van Egmond J, van Beem HB and Veth RP Monitoring during cryosurgery of bone tumors J Surg Oncol 1997, 65(I):40-45

26. Schreuder HW, van Egmond J, van Beem HB and Veth RP Monitoring during cryosurgery of bone tumors J Surg Oncol 1997, 65(I):40-45

27. Schreuder HW, Pruszczynski M, Veth RP and Lemmens JA Treatment of benign and low-grade malignant intramedullary chondroid tumours with curettage and cryosurgery Eur J Surg Oncol 1998, 24(2): 120-6

28. Seifert JK, Junginger $T$ and Morris DL A collective review of the world literature on hepatic cryotherapy J R Coll Surg Edinb 1998 , 43:14I-154

\section{Pre-publication history}

The pre-publication history for this paper can be accessed here:

http://www.biomedcentral.com/1471-2482/3/3/prepub
Publish with Bio Med Central and every scientist can read your work free of charge

"BioMed Central will be the most significant development for disseminating the results of biomedical research in our lifetime. "

Sir Paul Nurse, Cancer Research UK

Your research papers will be:

- available free of charge to the entire biomedical community

- peer reviewed and published immediately upon acceptance

- cited in PubMed and archived on PubMed Central

- yours - you keep the copyright

Submit your manuscript here:

http://www.biomedcentral.com/info/publishing_adv.asp
BioMedcentral 